\title{
A estética barroca da histeria: o feminino em questão
}

Percorrendo as páginas de Histeria: o princípio de tudo, da psicanalista Denise Maurano, parte da coleção Para ler Freud, organizada por Nina Saroldi e editada pela Civilização Brasileira, nos deparamos com um livro que vai além do objetivo de despertar o desejo de ler Freud e verificar a atualidade de suas construções. Somos brindados com uma demonstração do estilo singularíssimo de sua autora, que transforma a estética barroca em ferramenta de contextualização e chave interpretativa, imprescindíveis para melhor situar os fundamentos, a ética e a orientação que sustentam a teoria e a clínica psicanalíticas, das quais as histéricas foram fundadoras. Com vigor e força de transmissão, o trabalho contribui para os que iniciam suas incursões no campo psicanalítico e para os que, há muito, já se dedicam à causa do inconsciente.

Enriquece seu texto o valor concedido ao teatro da Antiguidade, e dos séculos XIX e XX, além da leitura da histeria

\footnotetext{
* Universidade Federal do Estado do Rio de Janeiro - UNIRIO (Rio de Janeiro, RJ. Br).
} 
através das lentes do barroco, tornando patente o gozo evocado pelas obras barrocas. Evidencia que o rebuscamento e a riqueza de detalhes, presentes nos anjinhos desnudos, com os olhinhos revirados e nas imagens de sangue, crânios e caveiras, próprios ao barroco, também são encontrados na histeria. As obras barrocas e a arquitetura histérica tendo em comum o fato de serem estruturas pautadas pela verdade do desejo, e que, "prevenidas quanto à inconsistência de um objeto que pudesse calar sua ânsia, dirigem-se para o mais além, visando um gozo de outra natureza" (p. 41).

O capítulo denominado "Nos bastidores: Freud entre a academia e o teatro" merece destaque. Descreve o contexto vivido por Freud em Viena, ao final do século XIX, e apresenta a imperatriz Elisabeth II, esposa de Francisco José I, imortalizada no cinema pela atriz Romy Schneider, personagem bela e rebelde que se tornou símbolo de uma época de grandes transformações, conferindo à histeria, no dizer de Denise Maurano, "uma visibilidade a mais" (p. 32). Demonstra que foi por um complexo caminho, marcado pelo feminino, que Freud chega à histeria e à Psicanálise. Diferentemente da tradição médica, o pai da Psicanálise não toma a teatralidade como farsa, mas acolhe-a como um modo particular de manifestar a verdade.

Assim, após ter lançado "luzes barrocas sobre a cena histérica", a autora acentua o foco sobre seu objeto, debruçando-se sobre os primeiros casos clínicos estudados por Breuer e Freud. Com elegância, demarca os principais aspectos desses atendimentos que tanto contribuíram para a constituição da psicanálise. Sob sua pena, revisitamos Ana O., Elisabeth e Dora, exemplos paradigmáticos da pesquisa clínica extremamente refinada que passa a se produzir a partir dessas escutas. Pesquisa que, partindo do trauma, alcança a fantasia, eixo fundamental para o acesso à verdade de um sujeito, que encontra no sintoma e na fantasia modos privilegiados de expressão.

Tomando com rigor a obra freudiana construída a partir do tema, "Histeria, o princípio de tudo", enlaça-a a comentários de Lacan. Dos primeiros estudos psicanalíticos, chegamos à distinção entre o desejo e o gozo e à máxima lacaniana de que "não há relação sexual", momentos de um trajeto que passa pela análise da estrutura defensiva da histeria, pelo enigma do feminino e pela insatisfação como marca de desejo nos histéricos.

A autora evidencia que a histeria, mais do que uma patologia qualquer, é uma gramática desejante, um modo particular de fazer laços e de operar com o desejo. Introduzi-la e reintroduzi-la, especialmente no cenário atual, onde a tendência organicista, influenciada pelos laboratórios farmacêuticos, chegou a erradicá-la das classificações psicopatológicas, é, como muito bem grifado no sumário, um imperativo. Se a fragmentação das psicopatologias em seus sintomas, proposta pelos DSMs, retira a subjetividade da psicopatologia 


\section{RESENHAS BIBLIOGRÁFICAS}

psiquiátrica e abre mão da organização imanente à pluralidade dos sintomas psíquicos, o livro não se configura apenas como um "manifesto em prol da histeria", como apontado pela autora, mas como um manifesto em prol do sujeito e de seu desejo.

Citação/Citation: Perez, L.M.F. (2015, dezembro). A estética barroca da histeria: o feminino em questão. Resenha do livro Histeria: o princípio de tudo. Revista Latinoamericana de Psicopatologia Fundamental, 18(4), 793-795.

Editor do artigo/Editor: Profa. Dra. Sonia Leite

Recebido/Received: 14.9.2015/ 9.14.2015 Aceito/Accepted: 29.10.2015 / 10.29.2015

Copyright: (C) 2009 Associação Universitária de Pesquisa em Psicopatologia Fundamental/ University Association for Research in Fundamental Psychopathology. Este é um artigo de livre acesso, que permite uso irrestrito, distribuição e reprodução em qualquer meio, desde que o autor e a fonte sejam citados / This is an open-access article, which permits unrestricted use, distribution, and reproduction in any medium, provided the original authors and sources are credited.

\section{Lucia Maria de Freitas Perez}

Psicanalista, membro do Corpo Freudiano Escola de Psicanálise - Seção Rio de Janeiro (Rio de Janeiro, RJ, Br); Doutora em Psiquiatria, Psicanálise e Saúde Mental, pelo IPUB/ Universidade Federal do Rio de Janeiro - UFRJ (Rio de Janeiro, RJ, Br); Professora Adjunta da UNIRIO - Universidade Federal do Estado do Rio de Janeiro (Rio de Janeiro, $\mathrm{RJ}, \mathrm{Br})$.

Av. Arquiteto Affonso Reidy, 244/101 - Barra da Tijuca

22620-270 Rio de Janeiro, RJ, Br

e-mail:1mfperez@uol.com.br

This is an open-access article, which permits unrestricted use, distribution,

\section{(cc) BY-NC} and reproduction in any medium for non-commercial purposes provided the original authors and sources are credited. 